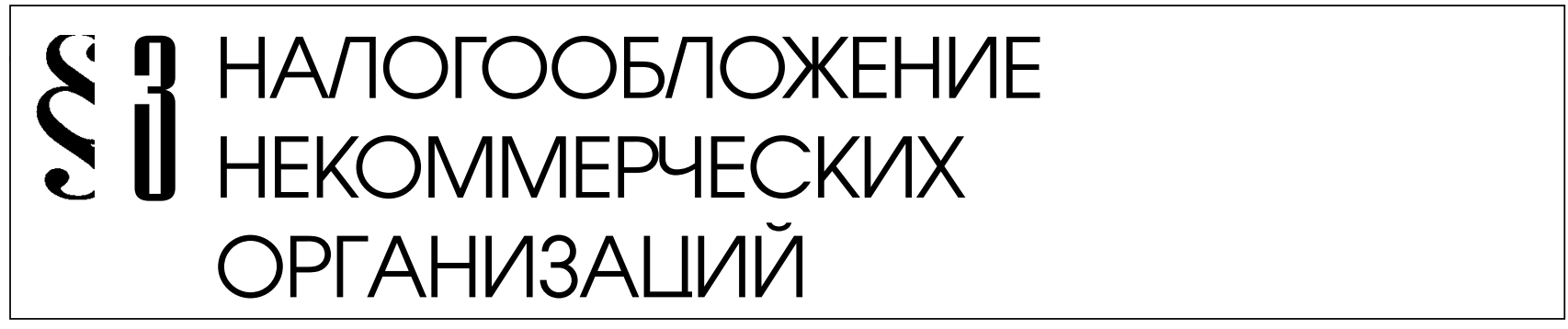

В.И. Гордин

\title{
ВНЕШНИЙ МУНИЦИПАЛЬНЫЙ ФИНАНСОВЫЙ КОНТРОЛЬ КАК ИНСТРУМЕНТ УТОЧНЕНИЯ НАЛОГОВЫХ ДОХОДОВ МУНИЦИПАЛИТЕТА
}

Аннотация: Реформирование бюджетной системы предполагает повышение эффрективности и качества управления общественными финансами на всех уровнях бюджетной системы страны, включая и ориентацию на повышение эффрективности местных бюджетов. В этой связи в статье проанализирована роль внешнего муниципального финансового контроля в уточнении налоговых доходов муниципалитета, поскольку на муниципальном уровне налоговые доходы, безусловно, являются определяющим фактором финансовой самостоятельности территорий, что выступает важнейшим критерием демократизации российского общества. Результаты деятельности органов внешнего муниципального финансового контроля существенным образом призваны влиять на бюджетные и социально-экономические процессы. Методологической основой исследования послужили научные труды отечественных ученых-экономистов в области реализации внешнего муниципального финансового контроля. В работе применены методы анализа и синтеза, дедукции и индукции. Современная система финансового контроля, согласно бюджетному кодексу РФ подразделяется на внешний и внутренний финансовый контроль. Осуществление и внутреннего и внешнего финансового контроля государства значимо для формирования и использования средств бюджетов всех уровней. Однако на наш взгляд, именно система внешнего финансового контроля государства должна обеспечить реализацию целостной бюджетной и финансовой политики страны, а также единство целей, принципов и согласованность действий в области контроля за федеральными, региональными и муниципальными бюджетными средствами. Деятельность контрольно-счетных органов муниципалитета имеет большое значение в регулировании и управлении налоговыми источниками доходной базы местных бюджетов через полномочия экспертизы проектов местного бюджета и контроля за его исполнением. На муниципальном уровне налоговые доходы, безусловно, являются определяющим фактором финансовой самостоятельности территорий, что составляет основу для экономического развития всего государства в целом.

Ключевые слова: муниципалитет, финансы, финансовый контроль, контрольно-счетный орган, налоговые доходы, бюджет, самостоятельность территории, социально-экономические прочессы, роль контроля, уточнение налоговых доходов.

кономическая самостоятельность местных органов власти является важнейшим критерием демократиза- ции общества. Эффективность бюджетных планов во многом определяет качество и своевременность оказания государствен- 
Структура доходной части бюджета Волгограда на 2012-2014 гг. (тыс. руб.)

\begin{tabular}{|l|c|c|c|c|c|c|}
\hline \multirow{2}{*}{ Показатели } & \multicolumn{2}{|c|}{$\mathbf{2 0 1 2}$ год } & \multicolumn{2}{c|}{$\mathbf{2 0 1 3}$ год } & \multicolumn{2}{c|}{$\mathbf{2 0 1 4}$ год } \\
\cline { 2 - 7 } & $\mathbf{\text { сумма }}$ & доля, \% & сумма & доля, \% & сумма & доля, \% \\
\hline $\begin{array}{l}\text { Налоговые } \\
\text { доходы }\end{array}$ & 6810975,0 & 49,5 & 9179994,0 & 70,6 & 9704946,0 & 71,3 \\
\hline $\begin{array}{l}\text { Неналоговые } \\
\text { доходы }\end{array}$ & 2344810,0 & 17,0 & & & & \\
\hline $\begin{array}{l}\text { Безвозмездные } \\
\text { поступления }\end{array}$ & 4592106,1 & 33,4 & 3812210,6 & 29,4 & 3891565,2 & 28,7 \\
\hline Итого: & 13747891,1 & 100,0 & 12992204,6 & 100,0 & 13596511,2 & 100,0 \\
\hline
\end{tabular}

Составлено автором по: Внутренние материалы Контрольно-счетной палаты Волгограда.

URL: http://www.kspvolg.ru.

ных и муниципальных услуг. В этой связи особое внимание уделяется грамотному определению бюджетных налоговых доходов как основы полного выполнения возложенных полномочий на органы местного самоуправления. В настоящее время на муниципальном уровне налоговые доходы, безусловно, являются определяющими для территорий. В структуре собственных доходов данные поступления занимают наибольший удельный вес, что видно из таблицы 1.

Большое значение в регулировании и управлении налоговыми источниками доходной базы местных бюджетов является деятельность органов внешнего муниципального финансового контроля.

В.В. Жадан определяет муниципальный финансовый контроль как «контроль за действиями должностных лиц, финансово-хозяйственной деятельностью получателей бюджетных средств либо иных субъектов, использующих средства или собственность местного бюджета, осуществляемый в целях выявления резервов увеличения доходных поступле- ний в бюджет и укрепления финансовой дисциплины» ${ }^{2}$

По мнению О.В. Шинкаревой, муниципальный финансовый контроль «является частью процесса местного самоуправления, заключающегося в осуществлении со стороны финансовых органов муниципальных образований, специальных учреждений и населения мониторинга по поводу законности и эффективности формирования, обращения и использования муниципальных фондов денежных средств, выявления резервов поступления дополнительных финансовых источников муниципалитетов и оптимизации расходования средств, а также улучшения финансовой дисциплины для дальнейшего развития территории» ${ }^{2}$.

\footnotetext{
1 Жадан В.В. Муниципальный финансовый контроль в системе бюджетных отношений: автореф. .... к.э.н. Краснодар, 2005. URL: http://www.dissercat.com/content/ munitsipalnyi-finansovyi-kontrol-v-sisteme-byudzhetnykhotnoshenii.

2 О системе муниципального финансового контроля // Аудит и финансовый анализ. - № 4. - 2011. URL: http://www.auditfin.com/fin/2011/4/01 01/01 01\%20.pdf.
} 
Д.Н. Слободчиков и С.В. Лозовский уточняют, что муниципальный финансовый контроль представляет собой «совокупность мер регулирования в финансовой сфере, направленных на обеспечение экономической безопасности России и соблюдение муниципальных интересов в процессе публичной финансовой деятельности» ${ }^{3}$.

Н.М. Гладких и Д.Ю. Ракитин подчеркивают, что «целью муниципального финансового контроля является контроль за исполнением местного бюджета, соблюдением установленного порядка подготовки и рассмотрения проекта местного бюджета, отчета о его исполнении, а также контроль за соблюдением установленного порядка управления и распоряжения имуществом, находящимся в муниципальной собственности» ${ }^{4}$.

Согласно бюджетному кодексу Российской Федерации (далее - РФ) финансовый контроль делится на внешний и внутренний.

Внешний финансовый контроль является контрольной деятельностью соответственно Счетной палаты Российской Федерации, контрольно-счетных органов субъектов Российской Федерации и муниципальных образований.

Внутренний финансовый контроль является контрольной деятельностью Министерства финансов РФ, Федеральной службы финансово-бюджетного надзора, органов государственного (муниципального) финансового контроля, являющихся соответственно органами исполнительной

\footnotetext{
3 Слободчиков Д.Н., Лозовский С.В. Государственный и муниципальный бюджетный контроль (на примере Камчатского края): Монография. - М.: Издательский дом «Экономическая газета», 2012. - 164 с.

4 Гладких Н.М., Ракитин Д.Ю. О финансовом контроле за деятельностью муниципальных исполнительных органов // Налоги (журнал). — 2009. —№ 3.
}

власти субъектов РФ, местных администраций, Федерального казначейства (финансовых органов субъектов РФ или муниципальных образований $)^{5}$.

Осуществление и внутреннего и внешнего финансового контроля одинаково значимо влияют на формирование и использование средств бюджетов всех уровней, однако, на наш взгляд, именно система внешнего финансового контроля должна обеспечить реализацию целостной бюджетной и финансовой политики страны, а также единство целей, принципов и согласованность действий в области контроля за бюджетными средствами.

В рамках осуществления полномочий органов внешнего муниципального финансового контроля возможно регулировать и управлять налоговыми источниками доходной базы местных бюджетов через:

- подготовку заключений к проекту решения представительного органа муниципалитета «0 бюджете на соответствующий период»;

- подготовку заключений о результатах рассмотрения годового отчета исполнительного органа муниципалитета «Об исполнении бюджета за соответствующий период»;

- участие в мероприятиях исполнительного органа муниципалитета по пополнению доходной части местного бюджета.

Так, например Контрольно-счетная палата Волгограда (далее - КСП) в рамках подготовки заключения к проекту решения Волгоградской городской Думы «0 бюджете Волгограда» на соответствующий

\footnotetext{
5 Бюджетный кодекс Российской Федерации от 31.07.1998 № 145-Ф3 (ред. от 28.12.2013) (с изм. и доп., вступ. в силу с 01.01.2014). В данном виде документ опубликован не был. Доступ из справочно-правовой системы «КонсультантПлюс». Первоначальный текст документа // Российская газета, № 153-154, 12.08.1998.
} 
временной период исследует прогнозируемый объем налоговых доходов на предмет уточнения параметров доходных источников с учетом социально-экономической ситуации в Волгограде.

Например, прогноз поступлений по налогу на доходы физических лиц (далее НДФЛ) в бюджет Волгограда оценивался администрацией Волгограда в размере 4907 471,8 тыс. руб. (по нормативу отчислений $38,82 \%$ ).

Управление Федеральной налоговой службы по Волгоградской области (далееУФНС) оценило общий сбор по НДФЛ на территории Волгограда в сумме 12968206 тыс. руб. Исходя из указанной суммы, прогноз поступлений по НДФЛ в местный бюджет оценивался администратором доходов (УФНС) в размере 5034 257,6 тыс. руб.

КСП отмечала, что данные администратора доходов (УФНС) представлены по итогам поступления НДФЛ за 9 месяцев в связи с чем, по итогам года могут подвергнуться корректировке.

Учитывая данные по прогнозу социально-экономического развития Волгограда, а также возможную корректировку планируемых поступлений администратором доходов, КСП считала возможным принять за основу расчет администрации Волгограда. При этом, учитывая темп роста фонда заработной платы относительно 2010 года (на 8789500 тыс. руб.), КСП считала возможным учесть в качестве дополнительного дохода по НДФЛ сумму в размере 50000 тыс. руб.

КСП, в рамках своих полномочий в течение 2012 года осуществляла и оперативный контроль за исполнением бюджета Волгограда (см. табл. 2).

Из приведенных в таблице 2 данных видно, что в целом в бюджет Волгограда в 2012 году поступило налоговых доходов больше относительно первоначально утвержденного плана на 85 180,7 тыс. руб., и на 82 346,7 тыс. руб. больше относительно уточненного показателя на конец отчетного года.

В течение 2012 года КСП анализировала основные причины, влиявшие на невыполнение плановых заданий по отдельным видам налоговых доходов, а также на увеличение поступлений по итогам 2012 года относительно 2011 года.

Так, например, КСП за 9 месяцев 2012 года рекомендовала администрации Волгограда рассмотреть вопрос о целесообразности внесения поправок в бюджет Волгограда на 2012 год, в том числе, предлагалось скорректировать поступления по единому налогу на вмененный доход в связи с сокращением поступлений. Соответствующие изменения были учтены, что позволило выполнить плановые назначения по единому налогу на вмененный доход.

По земельному налогу плановые назначения в 2012 г. перевыполнены на 31 275,5 тыс. руб. или на $3,4 \%$. По сравнению с 2011 годом поступления увеличились на 167 157,8 тыс. руб. или 21,5\%.

На объемы поступлений в основном оказало влияние погашение недоимки по земельному налогу бюджетными организациями. Наиболее крупные суммы поступили от ГБУ «Волгоградская областная клиническая больница № 1 » и ГБУ «Волгоградский областной онкологический диспансер № 1». Сумма погашения указанными организациями составляла 21 000,0 тыс. руб.

Участвуя в мероприятиях администрации Волгограда по пополнению доходной части бюджета Волгограда, КСП провела ряд аналитических мероприятий и разработала соответствующие предложения. 
Данные об исполнении налоговых доходов бюджета

Волгограда в 2012 г. (тыс. руб.)

\begin{tabular}{|c|c|c|c|c|c|c|c|}
\hline \multirow{2}{*}{$\begin{array}{c}\text { Наименование } \\
\text { показателей }\end{array}$} & \multicolumn{2}{|c|}{$\begin{array}{c}\text { Утверждено } \\
\text { бюджетом }\end{array}$} & \multirow{2}{*}{ Исполнено } & \multicolumn{2}{|c|}{$\begin{array}{c}\text { \% исполне- } \\
\text { ния }\end{array}$} & \multicolumn{2}{|c|}{ Отклонения } \\
\hline & $\begin{array}{c}\text { перво- } \\
\text { начально }\end{array}$ & $\begin{array}{c}\text { после } \\
\text { уточне- } \\
\text { ний }\end{array}$ & & $\begin{array}{c}\text { к } \\
\text { перв. } \\
\text { плану }\end{array}$ & $\begin{array}{c}\text { к } \\
\text { уточн. } \\
\text { плану }\end{array}$ & $\begin{array}{c}\text { от перв. } \\
\text { плана }\end{array}$ & $\begin{array}{l}\text { от уточн. } \\
\text { плана }\end{array}$ \\
\hline $\begin{array}{l}\text { Налог на доходы } \\
\text { физических лиц }\end{array}$ & 4946472,0 & 4946472,0 & 4984409,5 & 100,7 & 100,7 & +37937,5 & $+37937,5$ \\
\hline $\begin{array}{l}\text { Единый налог } \\
\text { на вмененный } \\
\text { доход для от- } \\
\text { дельных видов } \\
\text { деятельности }\end{array}$ & 694692,0 & 673512,0 & 675090,4 & 97,1 & 100,2 & $-19601,6$ & $+1578,4$ \\
\hline $\begin{array}{l}\text { Единый сель- } \\
\text { скохозяйствен- } \\
\text { ный налог }\end{array}$ & 6211,0 & 2620,0 & 2610,6 & 42,0 & 99,6 & $-3600,4$ & $-9,4$ \\
\hline $\begin{array}{l}\text { Налог на иму- } \\
\text { щество физиче- } \\
\text { ских лиц }\end{array}$ & 185551,0 & 185551,0 & 195303,5 & 105,2 & 105,2 & +9752,5 & +9752,5 \\
\hline $\begin{array}{l}\text { Земельный } \\
\text { налог }\end{array}$ & 913054,0 & 913054,0 & 944329,5 & 103,4 & 103,4 & $+31275,5$ & $+31275,5$ \\
\hline $\begin{array}{l}\text { Государствен- } \\
\text { ная пошлина }\end{array}$ & 103895,0 & 114000,0 & 113260,0 & 109,0 & 99,4 & $-740,0$ & $-740,0$ \\
\hline $\begin{array}{l}\text { Задолженность } \\
\text { и перерасчеты } \\
\text { по отмененным } \\
\text { налогам } \\
\text { и сборам }\end{array}$ & 100,0 & 17600,0 & 20152,2 & 201,5 & 114,5 & $+20052,2$ & $+2552,2$ \\
\hline $\begin{array}{l}\text { Всего налого- } \\
\text { вые доходы }\end{array}$ & 6849975,0 & 6852809,0 & 6935155,7 & 101,3 & 101,2 & +85180,7 & $+82346,7$ \\
\hline
\end{tabular}

Составлено автором по: Внутренние материалы Контрольно-счетной палаты Волгограда.

URL: http://www.kspvolg.ru.

Так:

- администрации Волгограда целесообразно усилить проведение информационно-разъяснительной работы среди субъектов малого и среднего предпринимательства по вопросу применения патентной системы налогоо- бложения на территории Волгограда, поскольку КСП отмечала крайне низкие темпы перехода субъектов малого и среднего предпринимательства на данный налоговый режим;

- администрации Волгограда необходимо наращивание активизации работы 
межведомственных комиссий по обеспечению поступлений налоговых и неналоговых доходов в бюджет Волгограда и обязательных взносов в государственные внебюджетные фонды с участием представителей УФНС России по Волгоградской области и территориальных налоговых органов Волгограда, поскольку КСП отмечала снижение качества работы вышеуказанных комиссий. Доля показателей налоговой задолженности в 2012 г. в общей доле всей имеющейся задолженности перед бюджетом Волгограда составляла 71\% или 704 075,0 тыс. руб. (от 994 620,0 тыс. руб.). Самый крупный показатель задолженности приходился на земельный налог в размере 257 000,0 тыс. руб. (26\%), и НДФЛ - 123 000,0 тыс. руб. (12\%).

Стоит отметить, что ряд показателей имеют довольно длительные пе- риоды времени, за которые они не претерпели существенных изменений, как в меньшую, так и в большую сторону, что может сигнализировать о появлении сумм задолженности безнадежных к взысканию и росту их числа на дальнейшую перспективу. Средний показатель погашенных сумм задолженности за последние три года (2011-2013 гг.) составил $65 \%$, что соответствует ежегодному среднему показателю в денежном выражении на сумму 134 457,3 тыс. руб.

Таким образом, по итогам статьи можно сделать вывод о том, что деятельность контрольно-счетных органов муниципалитета имеет большое значение в регулировании и управлении налоговыми источниками доходной базы местных бюджетов через полномочия экспертизы проектов местного бюджета и контроля за его исполнением.

\section{Библиография:}

1. Бюджетный кодекс Российской Федерации от 31.07.1998 № 145-ФЗ (ред. от 28.12.2013) (с изм. и доп., вступ. в силу с 01.01.2014). В данном виде документ опубликован не был. Доступ из справочно-правовой системы «КонсультантПлюс». Первоначальный текст документа // Российская газета, № 153-154, 12.08.1998.

2. Внутренние материалы Контрольно-счетной палаты Волгограда. URL: http://www. kspvolg.ru.

3. Гладких Н.М., Ракитин Д.Ю. О финансовом контроле за деятельностью муниципальных исполнительных органов // Налоги (журнал). — 2009. - № 3.

4. Жадан В.В. Муниципальный финансовый контроль в системе бюджетных отношений: автореф. ... к.э.н. - Краснодар, 2005. — URL: http://www.dissercat.com/content/ munitsipalnyi-finansovyi-kontrol-v-sisteme-byudzhetnykh-otnoshenii.

5. О системе муниципального финансового контроля // Аудит и финансовый анализ. № 4. - 2011. URL: http://www.auditfin.com/fin/2011/4/01_01/01_01\%20.pdf.

6. Слободчиков Д.Н., Лозовский С.В. Государственный и муниципальный бюджетный контроль (на примере Камчатского края): Монография. - М.: Издательский дом «Экономическая газета», 2012. - 164 с.

7. Степашин С.В. Государственный финансовый контроль в противодействии коррупции // Журнал зарубежного законодательства и сравнительного правоведения. 2012. - 3. - С. 15-17. 
8. О.В. Болтинова К вопросу о государственном финансовом контроле в Российской Федерации // Финансовое право и управление. - 2013. - 2. - С. 39-45. DOI: $10.7256 / 2310-0508.2013 .2 .9725$.

9. М. Б. Разгильдиева Теоретические проблемы бюджетно-правовой ответственности // Финансовое право и управление. - 2013. - 2. - C. 102-118. DOI: 10.7256/23100508.2013.2.9876.

10. Скоряков О.В. К вопросу о новом этапе реформирования законодательства о контрольно-счетных органах субъектов Российской Федерации и муниципальных образований // Административное и муниципальное право. - 2011. - 9. - С. 87-89.

11. Никиткова У.О.. Об эффективности практики местного налогообложения. // Налоги и налогообложение. - 2013. - № 12. - C. 877-884. DOI: .10.7256/18128688.2013.12.10238.

12. Меньшенина Н.Н., Антропова Ю.Ю., Коробейникова А.П.. Коррупция в современной России: изучение общественного мнения граждан мегаполисов (на примере г.г. Екатеринбурга и Владивостока). // Политика и Общество. — 2013. — № 12. - С. 14291438. DOI: .10.7256/1812-8696.2013.12.10328.

13. Агеев В. Н.. Ограничение прав и свобод муниципальных служащих как способ противодействия коррупции // Тренды и управление. - 2013. - № 3. - С. 72-81. DOI: .10.7256/2307-9118.2013.3.7244.

14. А.В Губницын. Прозрачность доступность и заинтересованность. Канадский рецепт вовлечения граждан в местное самоуправление. // Тренды и управление. - 2013. № 2. - C. 180-186. DOI: .10.7256/2307-9118.2013.2.6293.

15. Агузарова Л.А.. Проблемы формирования бюджетов муниципального образования в дотационном регионе (на материалах РСО-Алания). // Налоги и налогообложение. 2013. — № 4. — C. 279-285. DOI: .10.7256/1812-8688.2013.4.873.

\section{References:}

1. Byudzhetnyi kodeks Rossiiskoi Federatsii ot 31.07.1998 № 145-FZ (red. ot 28.12.2013) (s izm. i dop., vstup. v silu s 01.01.2014). V dannom vide dokument opublikovan ne byl. Dostup iz spravochno-pravovoi sistemy «Konsul'tantPlyus». Pervonachal'nyi tekst dokumenta // Rossiiskaya gazeta, № 153-154, 12.08.1998.

2. Vnutrennie materialy Kontrol'no-schetnoi palaty Volgograda. URL: http://www.kspvolg.ru.

3. Gladkikh N.M., Rakitin D.Yu. O finansovom kontrole za deyatel'nost'yu munitsipal'nykh ispolnitel'nykh organov // Nalogi (zhurnal). — 2009. — № 3 .

4. Zhadan V.V. Munitsipal'nyi finansovyi kontrol'v sisteme byudzhetnykh otnoshenii: avtoref. ... k.e.n. - Krasnodar, 2005. - URL: http://www.dissercat.com/content/munitsipalnyi-finansovyi-kontrol-v-sisteme-byudzhetnykh-otnoshenii.

5. O sisteme munitsipal'nogo finansovogo kontrolya // Audit i finansovyi analiz. - № 4. 2011. URL: http://www.auditfin.com/fin/2011/4/01_01/01_01\%20.pdf.

6. Slobodchikov D.N., Lozovskii S.V. Gosudarstvennyi i munitsipal'nyi byudzhetnyi kontrol' (na primere Kamchatskogo kraya): Monografiya. - M.: Izdatel'skii dom «Ekonomicheskaya gazeta», 2012. - $164 \mathrm{~s}$. 
7. Stepashin S.V. Gosudarstvennyi finansovyi kontrol' v protivodeistvii korruptsii // Zhurnal zarubezhnogo zakonodatel'stva i sravnitel'nogo pravovedeniya. - 2012. - 3. - C. 15-17.

8. O.V. Boltinova $\mathrm{K}$ voprosu o gosudarstvennom finansovom kontrole $\mathrm{v}$ Rossiiskoi Federatsii // Finansovoe pravo i upravlenie. - 2013. - 2. - C. 39-45. DOI: 10.7256/23100508.2013.2.9725.

9. M. B. Razgil'dieva Teoreticheskie problemy byudzhetno-pravovoi otvetstvennosti // Finansovoe pravo i upravlenie. - 2013. - 2. - C. 102-118. DOI: 10.7256/2310-0508.2013.2.9876.

10. Skoryakov O.V. K voprosu o novom etape reformirovaniya zakonodatel'stva o kontrol'noschetnykh organakh sub"'ektov Rossiiskoi Federatsii i munitsipal'nykh obrazovanii // Administrativnoe i munitsipal'noe pravo. - 2011. - 9. - C. 87-89.

11. Nikitkova U.O.. Ob effektivnosti praktiki mestnogo nalogooblozheniya. // Nalogi i nalogooblozhenie. — 2013. — № 12. - C. 877-884. DOI: .10.7256/1812-8688.2013.12.10238.

12. Men'shenina N.N., Antropova Yu.Yu., Korobeinikova A.P.. Korruptsiya v sovremennoi Rossii: izuchenie obshchestvennogo mneniya grazhdan megapolisov (na primere g.g. Ekaterinburga i Vladivostoka). // Politika i Obshchestvo. - 2013. — № 12. - C. 1429-1438. DOI: .10.7256/1812-8696.2013.12.10328.

13. Ageev V. N.. Ogranichenie prav i svobod munitsipal'nykh sluzhashchikh kak sposob protivodeistviya korruptsii // Trendy i upravlenie. — 2013. — № 3. — C. 72-81. DOI: .10.7256/23079118.2013.3.7244.

14. A.V Gubnitsyn. Prozrachnost' dostupnost' i zainteresovannost'. Kanadskii retsept vovlecheniya grazhdan v mestnoe samoupravlenie. // Trendy i upravlenie. - 2013. - № 2. C. 180-186. DOI: .10.7256/2307-9118.2013.2.6293.

15. Aguzarova L.A.. Problemy formirovaniya byudzhetov munitsipal'nogo obrazovaniya v dotatsionnom regione (na materialakh RSO-Alaniya). // Nalogi i nalogooblozhenie. - 2013. № 4. — C. 279-285. DOI: .10.7256/1812-8688.2013.4.873. 